\title{
Endoscopic closure of a large gastric mucosal defect after endoscopic submucosal dissection using a novel endoscopic string-with-knotter suture device
}

Complete defect closure after endoscopic submucosal dissection (ESD) could decrease delayed adverse events [1]. Although various endoscopic instruments are used to suture post-ESD defects, such as the Overstitch device [2] and loop string-assisted clip device [3], these devices either cost a lot or require complicated manipulation. Therefore, we developed a string-with-knotter device (VDK-FH-A-11-180; jiangsu Vedkang Medical Science and Technology Co., Changzhou, Jiangsu, China) [4] to easily and reliably close a gastric post-ESD defect ( $\vee$ Video 1$)$.

A 50-year-old woman with a submucosal lesion of the gastric lesser curve ( $\mathbf{F i g}$.

1 a) was referred for endoscopic treatment. A large defect with muscle injury was left after ESD had been performed ( Fig.1 b), which was sutured using the

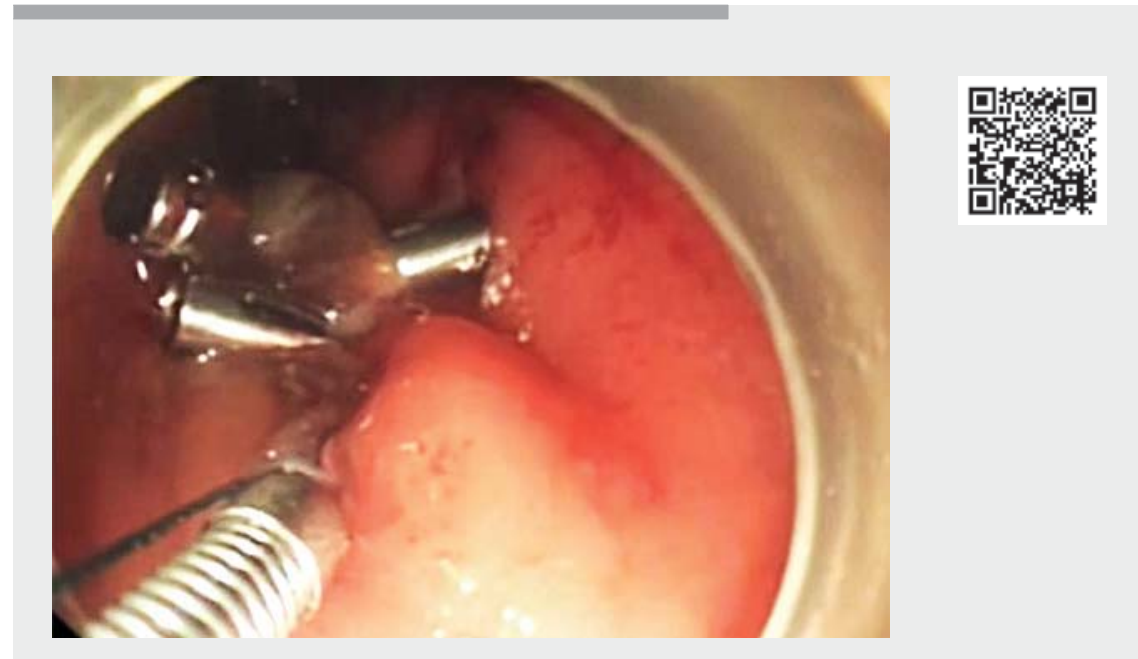

$\checkmark$ Video 1 Endoscopic closure of a large gastric mucosal defect after endoscopic submucosal dissection (ESD) using the novel string-with-knotter device. Three clips linked by a string are applied to the edges of the defect. The knotter device is then used to approximate the mucosal defect, tie the string, and cut the excess string. Additional endoscopic clips are placed to achieve complete closure.

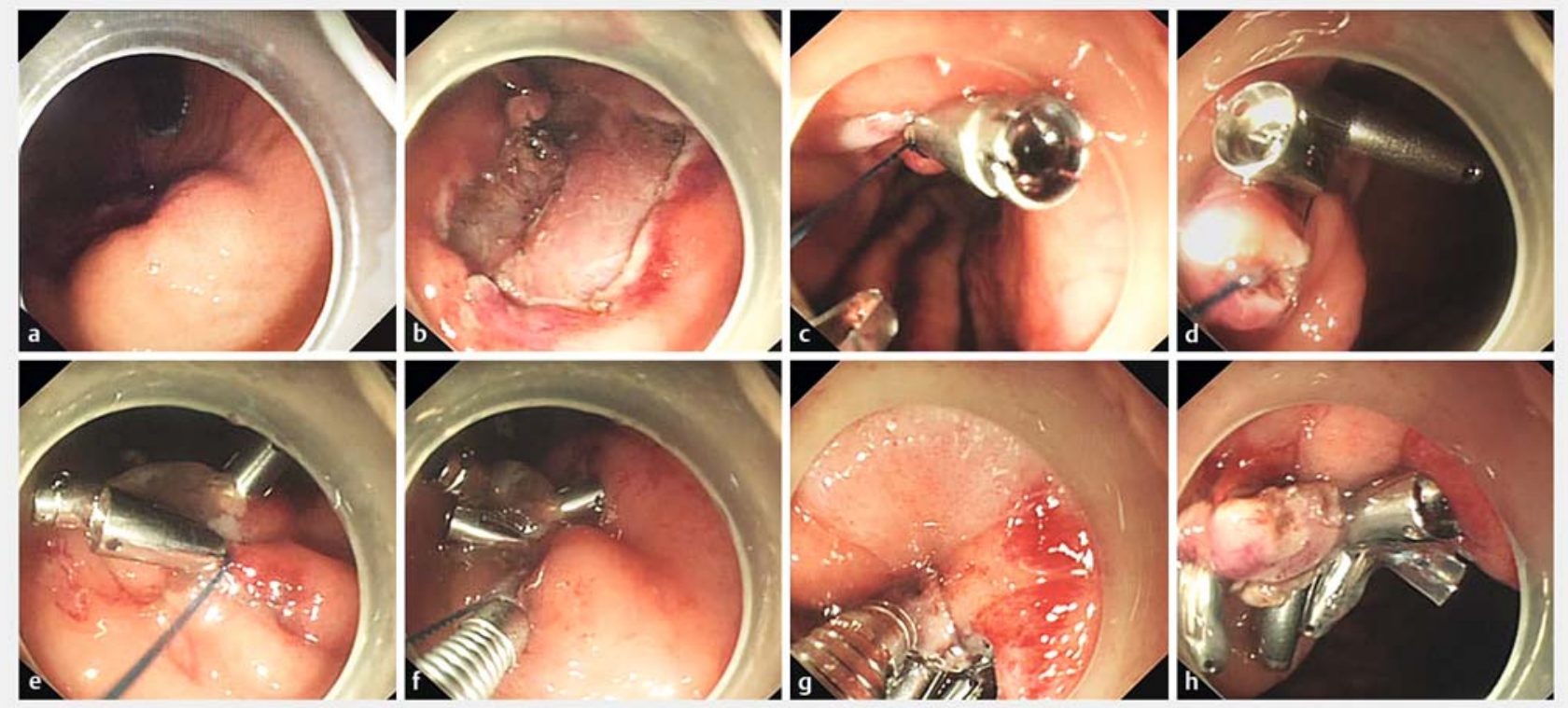

- Fig. 1 Endoscopic views of the closure of a large gastric mucosal defect after endoscopic submucosal dissection (ESD) using the novel stringwith-knotter suture device showing a a $2.5 \times 3.5 \mathrm{~cm}$ submucosal lesion located in upper lesser curve of the stomach; $\mathbf{b}$ a large $(4 \mathrm{~cm})$ mucosal defect with muscle layer injury following ESD; $\mathbf{c}$ a clip with attached string that was placed in the middle of the lesser curve edge of the mucosal defect; $\mathbf{d}$ another clip that was hooked over the string and then fixed to the middle of the contralateral edge of the mucosal defect; $\mathbf{e}$ the third clip that was deployed to anchor the string to the anal margin of the mucosal defect; $\mathbf{f}$ the mucosal defect after it had been markedly gathered in by introducing the knotter and pulling the free end of the string; $\mathbf{g}$ sequential clips placed to completely close the mucosal defect after the string had been perfectly tied and the redundant string had been cut by the knotter; $\mathbf{h}$ complete closure of the post-ESD defect by the suture device. 

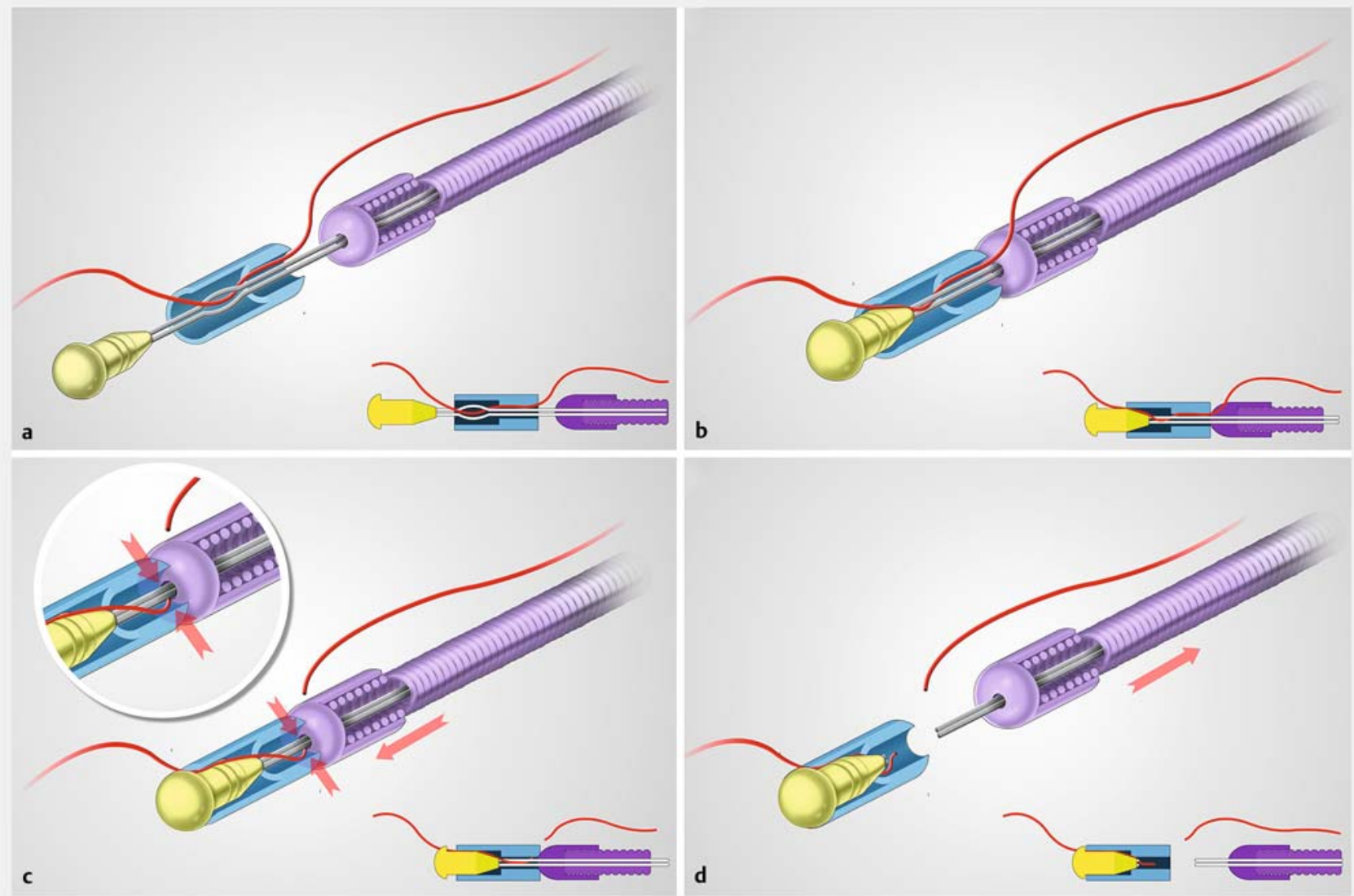

- Fig. 2 Schematic diagrams to illustrate the working mechanisms of the string-with-knotter device showing: a the preparation of the knotter device with the string (red) first passed through the outer big plastic cylinder (blue) and then run across the inner scissors formed from the two steel wires (gray); $\mathbf{b}$ the knotting of the suture string as the plastic locking cylinder is pushed by the metal sheath (purple) to precisely cover the metal locking head (yellow), with enough force of friction being provided to fix the sting in-between the wires; $\mathrm{c}$ the cutting of excess string, which occurs when the plastic locking cylinder is further pushed by the metal sheath, so that the two steel wires are severely compressed and provide shear force to cut off the string between the wires; $\mathbf{d}$ the release of the tied string that occurs when the integrated plastic cylinder and metal locking head are continuously pushed by the metal sheath while the two steel wires are pulled away from the metal head, thereby increasing the counter-force between the metal head and steel wires until the welding strength is gradually surpassed, so it ruptures and two elements are completely separated.

string-with-knotter device. A reopenable clip with string attached was deployed on the middle of the lesser curve edge of the defect ( $>$ Fig.1 c). Another clip was used to pick up the string and was placed on the opposite edge of the defect ( $\vee$ Fig. 1d). The third clip was used to fix the string to the anal edge of the defect ( $\triangleright$ Fig.1e). The knotter was introduced over the string to approximate the defect by gradually pulling the free end of the string ( $\triangleright$ Fig.1f). Because the string passed successively through the outer plastic cylinder and the inner two steel wires ( $>$ Fig. 2 a), when the plastic cylinder was continuously pushed by the metal sheath, advancing it towards the metal head, the string was firstly tied via the force of friction between the plastic cylinder and the metal head ( $>$ Fig. 2 b), then excess string was cut under shear force from severe compression of the two steel wires ( $\mathbf{F i g} \cdot \mathbf{2} \mathbf{c}$ ). Finally, the tied string was released as the welding site ruptured owing to the counter-force between the steel wires and the metal head ( Fig. 2d). Additional clips were then placed ( $\triangleright \mathbf{F i g . 1} \mathbf{g}$ ), and endoscopic inspection confirmed complete defect closure ( $\mathbf{F i g . 1} \mathbf{~ h}$ ).

Inspired by the widely used string-clip suturing method [5], this novel suture device beautifully solves the difficulty in knotting and cutting the string, so may be a promising closure method for large gastrointestinal defects and perforations.

Endoscopy_UCTN_Code_CCL_1AZ_2AO

\section{Competing interests}

The authors declare that they have no conflict of interest. 
Wei-hui Liu' ${ }^{1}$, Zhao-shen Li $^{2}$, Dong Wang ${ }^{3}$

1 Department of Gastroenterology and Hepatology, Sichuan Academy of Medical Sciences \& Sichuan Provincial People's Hospital, Chengdu, Sichuan Province, China

2 Department of Gastroenterology, Changhai Hospital, Second Military Medical University and Naval Medical University, Shanghai, China

3 Department of Gastroenterology, Ruijin Hospital, Shanghai Jiaotong University School of Medicine, Shanghai, China

\section{Corresponding author}

\section{Dong Wang, MD, PhD}

Department of Gastroenterology, Ruijin Hospital, Shanghai Jiaotong University School of Medicine, Shanghai, China dr.dongwang@qq.com
[1] Goto O, Oyama T, Ono H et al. Endoscopic hand-suturing is feasible, safe, and may reduce bleeding risk after gastric endoscopic submucosal dissection: a multicenter pilot study (with video). Gastrointest Endosc 2020; 91: 1195-1202

[2] Chon SH, Toex U, Plum PS et al. Successful closure of a gastropulmonary fistula after esophagectomy using the Apollo Overstitch and endoscopic vacuum therapy. Endoscopy 2018; 50: E149-E150

[3] Hu X, Xu QW, Liu WH. Endoscopic loop string-assisted clip suturing closure of large mucosal defects after endoscopic submucosal dissection in the sigmoid colon. Am J Gastroenterol 2020; 115: 15

[4] Wang Z], Li SY, Zhang YH et al. Endoscopic closure of large colonic perforations with a novel endoscopic clip device: An animal study (with videos). J Gastroenterol Hepatol 2019; 34: 2152-2157

[5] Nishizawa T, Akimoto T, Uraoka T et al. Endoscopic string clip suturing method: a prospective pilot study (with video). Gastrointest Endosc 2018; 87: 1074-1078
Bibliography

Endoscopy 2022; 54: E19-E21

DOI 10.1055/a-1348-0645

ISSN $0013-726 \mathrm{X}$

published online 17.2.2021

(c) 2021. Thieme. All rights reserved.

Georg Thieme Verlag KG, Rüdigerstraße 14 , 70469 Stuttgart, Germany

\section{ENDOSCOPY E-VIDEOS}

https://eref.thieme.de/e-videos

回回 Endoscopy E-Videos is a free

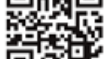
access online section, reporting 田: on interesting cases and new techniques in gastroenterological endoscopy. All papers include a high quality video and all contributions are freely accessible online.

This section has its own submission website at https://mc.manuscriptcentral.com/e-videos 